\title{
Treinamento e excelência organizacional: um estudo de caso na Pousada do Sandi, Paraty-RJ
}

\author{
Training and organizational excellence. A case study at Pousada do Sandi, Paraty-RJ \\ Entrenamiento y la excelencia organizacional. Un estudio de caso en la Posada do Sandi, \\ Paraty-RJ
}

Resumo: Um dos desafios da hotelaria contemporânea é alcançar patamares de excelência em um mercado tão competitivo, heterogêneo e dinâmico. Para tanto, um exímio controle da qualidade apresenta-se como uma das pilastras essenciais a esta prática, assim como uma eficaz política de treinamento deve ser vista como essencial ao desenvolvimento e aprimoramento de colaboradores, tornando-os mais flexíveis, proativos, assertivos e ágeis. Dito isso, este estudo de caso - que teve como objeto de análise a Pousada do Sandi, situada em Paraty, RJ - investigou como práticas de treinamento repercutem sobre desempenhos e imagens organizacionais. Para isso, os autores utilizaram análises quanti-qualitativas que aferiram as atividades operacionais dos setores de recepção e de governança desta pousada. Pelo viés quantitativo, por meio de questionários semiestruturados, colaboradores e gestores departamentais expuseram suas percepções sobre o nível de qualidade de seus afazeres e de seus setores. Já pelo viés qualitativo, entrevistas realizadas com a gerente geral propiciaram uma compreensão sobre como os preceitos de qualidade e excelência são aplicados nas políticas de treinamentos dessa pousada. Some a estes dois vieses uma análise do grau de satisfação dos hóspedes - retratada no TripAdvisor, Booking.com, Kayak e Expedia. Tais mapeamentos permitiram a ponderação de que as práticas de treinamento, conduzidas pelos gerentes departamentais desta pousada, obtêm resultados significativos no que tange à qualidade dos serviços ofertados.

Palavras-chave: Análise operacional. Capital Humano. Gestão hoteleira. Treinamento organizacional.

Abstract: One of the challenges of modern hotel business is reaching excellence in a very competitive, heterogeneous and dynamic market. For this purpose, an efficient quality control is one of the essential pillars for this practice, as well as an efficient training program policy, which should be essential for professional developing and improvement, making these professionals more resilient, proactive, assertive and responsive. That said, this case study - which was based on Pousada do Sandi, located in Paraty, RJ - investigated how training program policies impact organizational performance and image. Therefore, the authors used quanti-qualitative analyses that measured operational activities from reception and governance in this lodging. By using a quantitative analysis, through semi-structured questionnaire, employees and departmental managers exposed their perceptions about the level of quality in their duties and sectors. By using a qualitative analysis, interviews with the general manager provided an understanding of how quality and excellence precepts are verified in training program policy of this inn. In addition to these two analyses, we verified the degree of guests' satisfaction - presented in TripAdvisor, Booking.com, Kayak and Expedia. These surveys allowed the following consideration: training program policy reaches significant result in terms of quality of service offered in Pousada do Sandi.

Keywords: Operational analysis. Human Capital. Hotel management. Organizational training.

Resumen: Uno de los retos del sector hotelero contemporáneo es alcanzar niveles de excelencia en un mercado tan competitivo, heterogéneo y dinámico. Para estos fines, un eximio controle de calidad se presenta como una de las pilastras esenciales a esa práctica, así como una eximia política de entrenamiento debe ser vista como esencial en el desarrollo y mejora de empleados, haciéndolos más flexibles, proactivos, asertivos y ágiles. Dicho esto, este estudio de caso - que tuve como objeto de análisis la Posada do Sandi, situada en Paraty, RJ - investigó como prácticas de entrenamiento repercuten sobre el desempeños e imágenes organizacionales. Para eso, los autores se han valido de análisis cuanti-cualitativas que han evaluado las actividades operacionales de los sectores de

${ }^{1}$ Formação/curso: Doutor em Sistemas de Gestão Sustentáveis. Instituição: Universidade Federal Rural do Rio de Janeiro. E-mail: profrodrigoamado@gmail.com

${ }^{2}$ Formação/curso: Bacharel em Hotelaria. Instituição: Universidade Federal Rural do Rio de Janeiro. E-mail: patriciadsjorge@ gmail.com 
recepción y de gobernanza de esa posada. A través de análisis cuantitativos, por medio de cuestionarios semiestructurados, empleados y gestores departamentales han expuesto sus percepciones sobre el nivel de calidad de sus tareas y de sus sectores. Ya por el enfoque cualitativo, entrevistas realizadas con el gerente general propiciaron una comprensión sobre como los preceptos de calidad y excelencia son aplicados en las políticas de entrenamiento de esta posada. Somete a estos dos análisis el grado de satisfacción de los huéspedes - retractado en TripAdvisor, Booking.com, Kayak y Expedia. Tales asignaciones han permitido la ponderación de que las prácticas de entrenamiento, conducidas por los gerentes departamentales de esa posada, tienen resultados significativos en lo que se refiere la calidad de los servicios ofertados.

Palabras Clave: Análisis operativo. Capital Humano. Gestión hotelera. Entrenamiento organizacional.

\section{Introdução}

Apesar da insegurança político-econômica mundial observada desde 2008, a cadeia produtiva do turismo tem crescido consideravelmente nestes últimos anos (EMBRATUR, 2015). De 2008 a 2016 essa atividade experimentou um crescimento de 30,83\% em seus deslocamentos internacionais, indo de 922 milhões para 1.235 bilhão. Do ponto de vista econômico, obteve um aumento de 18,19\% em suas receitas, indo de US\$ 1.1 trilhão (5\% do PIB) para US\$ 1.3 trilhão (10\% do PIB) (UNWTO, 2008; UNWTO, 2016).

Dentre suas inúmeras ofertas, uma das que mais se destaca é o setor hoteleiro, devido às suas mais variadas facilidades de recreação, entretenimento e conferências que acabam aquecendo a economia local (BUIJTENDIJK; TSCHUNKERT, 2016). Em específico ao cenário brasileiro, de 2011 a 2016, esse setor experimentou um crescimento de $15 \%$ em suas capitais (IBGE, 2017). Ademais, em 2016, propiciou uma receita de aproximadamente $\mathrm{R} \$ 144$ bilhões - valor estimado a partir do número total de unidades habitacionais registradas no Brasil (1.011.254) (IBGE, 2017), acompanhado por sua taxa de ocupação $(56,5 \%)$ e diária média (R\$ 252,00) (FOHB, 2017).

Em vista destas descrições, um dos desafios dos gestores hoteleiros contemporâneos é alcançar a excelência organizacional em um mercado tão competitivo, heterogêneo e dinâmico (CENTURIÓN, 2014). Isso depende de um exímio controle da qualidade dos processos de planificação, dos métodos organizacionais, dos recursos materiais e imateriais e da gestão do conhecimento que ali serão orquestrados (UBEDA-GARCIA et al., 2013; ROBLEDO; ARÁN; PÉREZ-ARANDA, 2015; CHERAGHALIZADEH; TÜMER, 2017).

Por conseguinte, ainda que o progresso tecnológico tenha acarretado inovações significativas nas operações hoteleiras, Ubeda-García et al. (2014) afirmam que o elemento humano permanece como peça fundamental para se alcançar a excelência organizacional. Esta, por sua vez, necessita que os seguintes princípios sejam assimilados - de maneira contínua, permanente, proprietária e progressiva (CASTELLI, 2005) - por gestores e colaboradores: total satisfação do cliente; gerência participativa; gerência de processos; constância de propósitos; delegação; disseminação de informações; garantia da 
qualidade; não aceitação de erros; desenvolvimento de competências; e aperfeiçoamento contínuo (VIEIRA, 2004; CASTELLI, 2005; CORRÊA; CAON, 2016).

Para que todos esses princípios se concretizem, é imprescindível que os gestores hoteleiros promovam ininterruptas práticas de treinamento que busquem propiciar qualidade, confiabilidade, conformidade e desempenho assertivos (FU; YANG; CHU, 2014). Desse modo, os treinamentos organizacionais objetivam incutir, aprimorar e desenvolver habilidades, capacidades, atitudes, conhecimentos e competências em seus participantes, influenciado positivamente os graus de suas motivações (UBEDA-GARCIA et al., 2013). Ademais, uma vez bem sistematizada, tais práticas instigam seus integrantes a desempenhar suas funções com alto índice de qualidade, assertividade e compromisso (BOOG, 2013) - prerrogativas que, paralelamente, também auxiliam na elevação da produtividade organizacional (FERRARY, 2015).

Desse modo, ao investir em treinamento, uma organização hoteleira garante um corpo de colaboradores apto a desenvolver, de maneira eficaz, eficiente e ágil, suas atividades diárias (SANTOS; SILVA, 2015), permitindo-lhe construir práticas operacionais ou gerenciais valiosas e difíceis de "serem copiadas" ou substituídas e que se tornarão uma sólida vantagem competitiva (ESTEBAN-LLORET; ARAGÓN-SÁNCHEZ; CARRASCO-HERNÁNDEZ, 2014).

Nesse sentido, o escopo analítico deste trabalho se sustenta na premissa de que a satisfação dos hóspedes ocorre através de uma oferta de qualidade, que consiga não só atender suas necessidades, como também superar suas expectativas (SANTOS; SILVA, 2015). Algo que de fato só se sustenta e se perpetua se os gestores hoteleiros equacionarem uma política de treinamento que pleiteiem não só o aperfeiçoamento de desempenhos, condutas, competências, técnicas, habilidades e conhecimentos, mas que também contemple o aprimoramento das relações interpessoais e interdepartamentais frente às inovações, tendências, oportunidades e ameaças de seu mercado (PETROCCHI, 2002; GOMES; TEODORO, 2010; UBEDA-GARCIA et al., 2013; BAUM, 2015).

Exposto isso, o referido trabalho objetivou evidenciar, por meio de um estudo de caso - pautado por preceitos quanti-qualitativos - a importância que os processos de treinamento assumem perante a qualidade dos serviços ofertados em uma empresa hoteleira, observando suas implicações sobre os desempenhos e imagem organizacional. Desse modo, a organização escolhida para a realização desta pesquisa foi a Pousada do Sandi, localizada no município de Paraty, região Costa Verde do Estado do Rio de Janeiro.

A escolha por esse estabelecimento se deu pelo fato de possuir grande representatividade entre os meios de hospedagem do município. De acordo com a Associação de Hotéis Roteiros de Charme (s/d), esta pousada é identificada como um dos mais belos cartões postais de Paraty, tornando-se um dos meios de hospedagem favoritos dos turistas paratienses. Fato explicado pela importância cultural de sua 


\section{POUSADA DO SANDI, PARATY-RJ.}

edificação, que possui 300 anos de histórias, memórias, designs e decorações que remetem ao período do Brasil Colônia. Dessa maneira, justificada a escolha do objeto de pesquisa, este estudo buscou responder ao seguinte questionamento: de que maneira os programas de treinamento influenciam a qualidade, os resultados e a imagem do meio de hospedagem investigado?

Dessa forma, os resultados alcançados apontaram que os treinamentos, conduzidos pelos gerentes departamentais desta pousada, obtém resultados significativos não só sobre a qualidade de seus serviços, como também oportunizam meios para a padronização operacional e para a motivação de seus funcionários, garantindo-lhes meios para exercerem suas funções de forma mais confiante, objetiva e proativa.

\section{Marco Teórico}

O segmento hoteleiro evidencia-se como um complexo sistema comercial, constituído por um conjunto emaranhado de infraestruturas, equipamentos, produtos, serviços e atendimentos que intenta satisfazer uma pluralidade de necessidades de seus stakeholders (SANTOS; SILVA, 2015; CASTELLI, 2016). A partir desses dinâmicos conjuntos, seus gestores devem não apenas atender, mas superar as expectativas de suas demandas, de maneira que estas se tornem habitués (HAYES; NINEMEIER, 2005; GREGSON, 2009).

Para tanto, a obrigatoriedade de se orquestrar tais conjuntos por meio de um elevado padrão de qualidade torna-se vital para que seus processos não apenas superem as expectativas de seus consumidores, como também prospectem vantagens competitivas (ESTEBAN-LLORET; ARAGÓNSÁNCHEZ; CARRASCO-HERNÁNDEZ, 2014) que, segundo Cheraghalizadeh e Tümer (2017), podem ser alcançadas através do reconhecimento de seis variáveis (Figura 1) e suas implicações sobre o planejamento e controle da produção hoteleira.

Gestores que não conseguem entender as implicações dessas variáveis sobre seus resultados organizacionais prospectarão políticas de treinamento ineficazes, gerando elevados níveis de desapontamento, indiferença, confusão e ansiedade em seus ambientes de trabalho (CHERAGHALIZADEH; TÜMER, 2017). Por conseguinte, as empresas hoteleiras que não compreenderem as especificidades de cada uma dessas variáveis e suas implicações sobre seus resultados organizacionais aos poucos perderão seus markets shares, passando por uma gradativa obliteração (CENTURIÓN, 2014).

Figura 1 - Variáveis que implicam sobre a constituição de vantagens competitivas 


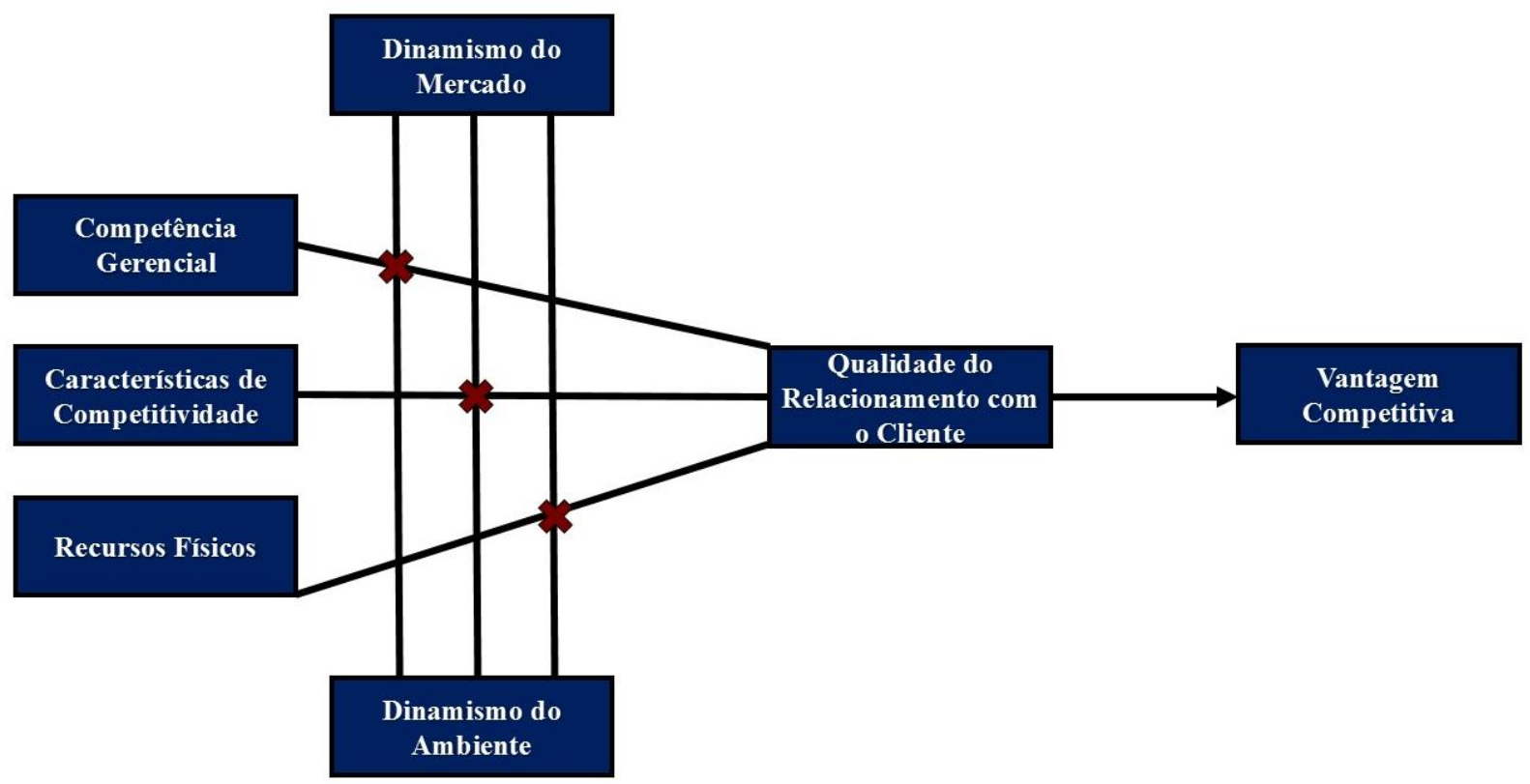

Fonte: Cheraghalizadeh e Tümer (2017, p. 267). Adaptado pelos autores.

Isto posto, um aspecto pertinente a se destacar é o fato de essas prerrogativas estarem centradas em um mercado - o hoteleiro - altamente volátil, cuja lógica vigente exalta o binômio “qualidade/produtividade" (CASTELLI, 2005). Nesse sentido, Conceição, Fraga e Conceição (2016) mencionam que a ausência deste binômio impacta diretamente o nível de satisfação dos hóspedes. Como prova disso, tais autores afirmaram que 78,8\% dos fatores que definem a apreciação de um serviço hoteleiro podem ser assim percebidos: $23,5 \%$ - relacionamento com o cliente; $20,6 \%$ - treinamento de pessoal; 20,3\% - ambiente; e 14,4\% - colaboração. A partir disso é possível notar que, direta ou indiretamente, o panorama exaltado por estes últimos autores possibilita uma importante alusão à temática da qualificação dos profissionais de hotelaria.

De maneira objetiva, pode-se dizer que os programas de qualificação possuem a finalidade de orientar e fornecer uma visão realista de funções que resultem nos reforços de compromissos e lealdades individuais, minimizando, por exemplo, os efeitos do turnover e de possíveis choques de papéis aos recém-chegados (YANG, 2010). Dessa maneira, através de suas especificidades, tem-se a oportunidade de elaborar relevantes estratégias contemporâneas (MICHAELS; HANDFIELD-JONES; AXELROD, 2002). Mais do que isso, oportunizam também a inserção de outra variável relevante: a do desenvolvimento profissional. De forma sucinta, pode-se dizer que as práticas de treinamento buscam a qualificação/aprimoramento de habilidades, competências, técnicas ou conhecimentos necessários ao desempenho de certas tarefas. Já os programas de desenvolvimento intencionam aperfeiçoar a visão sistêmica e holística dos colaboradores, de maneira que estes consigam galgar novas posições táticas ou estratégicas em seus estabelecimentos (MARRAS, 2011; CHERAGHALIZADEH; TÜMER, 2017). 
Notoriamente, a correlação "treinamento e desenvolvimento" deve ser vista como aspecto vital à sobrevivência dos meios de hospedagem modernos (VIEIRA; SALVE; CORRÊA, 2010; SILVA; LÚCIO; BARRETO, 2013). Afinal de contas, quanto melhores os desempenhos dos colaboradores, melhores serão os resultados organizacionais e os níveis de satisfação e lealdade dos hóspedes (YANG, 2010). Dito isso, para que estes programas ocorram de forma plena e assertiva, há a obrigatoriedade dos gestores otimizarem uma contundente gestão de pessoas e do conhecimento (SILVA; LÚCIO; BARRETO, 2013).

Conforme outrora ressaltado, as políticas de treinamento e desenvolvimento organizacional oportunizam a lapidação de competências, habilidades, técnicas, conhecimentos em níveis operacionais, táticos e estratégicos, bem como abarcam condutas, posturas e relacionamentos que garantirão um exímio controle de qualidade, além da prospecção da inovação organizacional (VIEIRA; SALVE; CORRÊA, 2011; FU; YANG; CHU, 2014).

Tais aspectos, se bem planejados e monitorados, permitem a elevação de resultados econômicos e de desempenhos organizacionais das empresas hoteleiras (ESTEBAN-LLORET; ARAGÓNSÁNCHEZ; CARRASCO-HERNÁNDEZ, 2014). Todavia, Robledo, Arán e Pérez-Aranda (2015) condicionam o sucesso dessas práticas ao conhecimento que os gestores possuem sobre seus colaboradores, suas demandas organizacionais e as exigências de seus consumidores.

Já Ubeda-Garcia et al. (2013) apresentam uma visão um pouco mais complexa sobre este assunto. Para esses autores, os programas de treinamento possuem correlação direta ao desempenho organizacional. Dessa maneira, para que obtenham êxito, as planificações devem perpassar por uma análise complexa, indissociável e interdependente dos seguintes fatores: (1) variáveis controláveis, como por exemplo, a classificação, a tipologia, o segmento de mercado; (2) as necessidades, objetivos e métricas de implementação e avaliação das estratégias de qualificação dos recursos humanos; (3) os resultados laborais pretendidos, o nível desejado de satisfação do consumidor e os índices almejados de produtividade e de performance financeira (Figura 2).

Assim, a partir desses preceitos, torna-se fundamental que as políticas de treinamento sejam estruturadas de forma ininterrupta e progressiva, para que possam promover (UBEDA-GARCIA et al., 2013; UBEDA-GARCIA et al., 2014; FERRARY, 2015; ROBLEDO; ARÁN; PÉREZ-ARANDA, 2015):

- a exposição de atributos, papéis e lógicas operacionais e gerenciais, estimulando os trabalhadores a galgar novos espaços e competências dentro de suas organizações;

- a redução do turnover organizacional;

- o estabelecimento de estratégias para a redução de custos correlacionados ao desperdício ou ineficiência laboral; 
TREINAMENTO E EXCELÊNCIA

ORGANIZACIONAL: UM ESTUDO DE CASO NA

POUSADA DO SANDI, PARATY-RJ.

- melhores performances financeira e organizacionais.

Figura 2 - Modelo Teórico que vincula treinamento e desempenho organizacional.

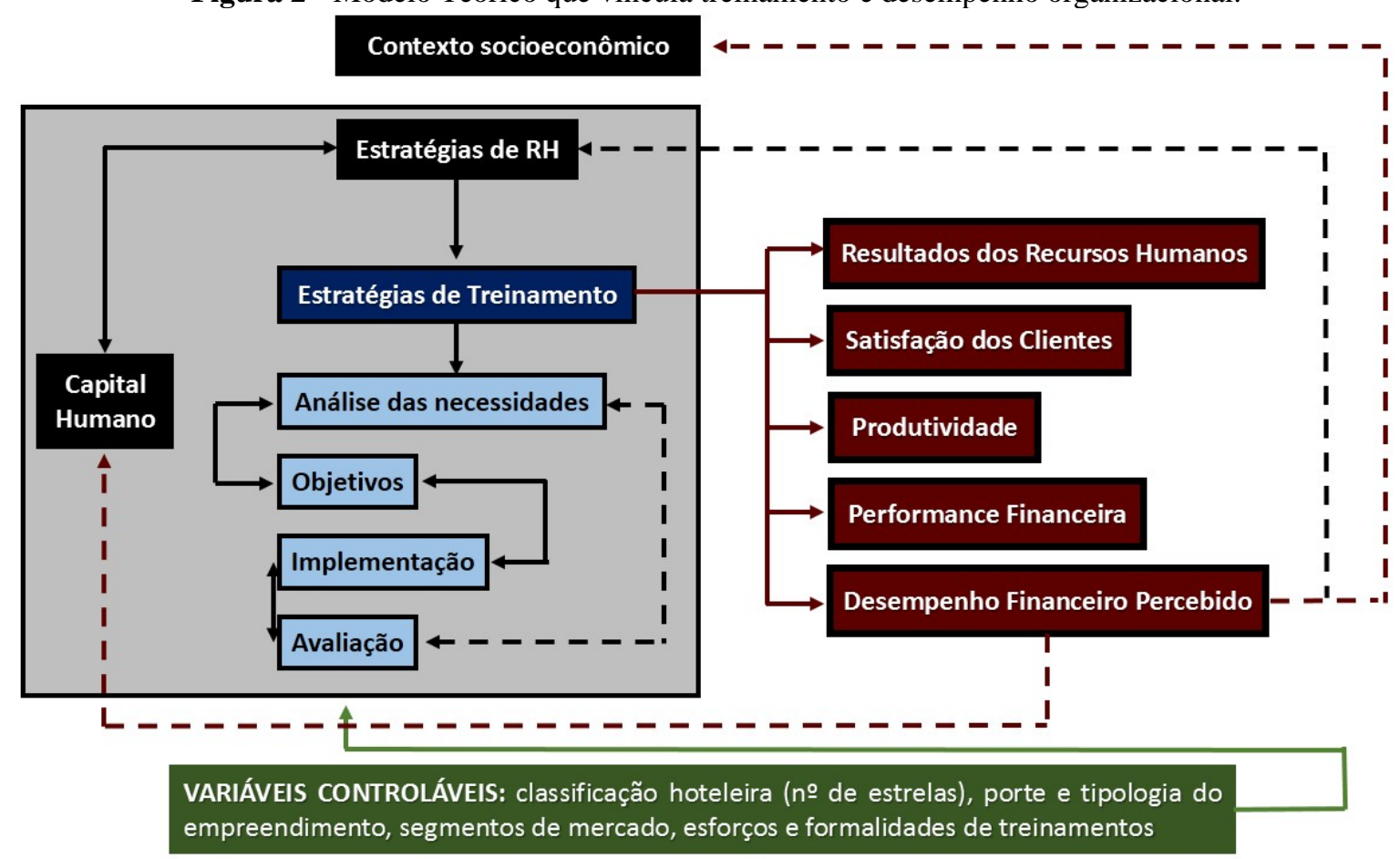

Fonte: Ubeda-Garcia et al. (2013, p. 389). Adaptado pelos autores.

Isto posto, também é fundamental que estas políticas incorporem os preceitos estabelecidos na missão, visão e nos valores organizacionais, auxiliando a construção de uma relação harmônica, produtiva e eficiente entre empresa e stakeholders (BAUM, 2015), capaz de gerar benefícios a curto, médio e longo prazo.

Pela ótica do curto e do médio prazo, as ações de treinamento objetivam moldar conhecimentos, habilidades e técnicas para um propósito definido. Neste momento, a ideia é de que as tarefas abarcadas por esses procedimentos possam ser desempenhadas com maiores e melhores eficácias, eficiências, assertividades e agilidades (MARRAS, 2011; FERRARY, 2015), assegurando disseminações de valores que permitam que seus participantes compreendam o sentido de suas tarefas/responsabilidades e se sintam à vontade em suas organizações (UBEDA-GARCIA et al., 2013). Pela perspectiva do longo prazo, tais práticas são capazes de mudar atitudes, condutas e comportamentos, contribuindo decisivamente para a satisfação, motivação e melhora de desempenhos - individuais, coletivos e organizacionais - através de uma gradativa internalização de conceitos, valores e da aprendizagem de novas habilidades (VARGAS, 1996).

Levando em consideração os aspectos até aqui ilustrados, pondera-se o quão relevante estes discursos são para as organizações hoteleiras. Afinal de contas, a experiência da hospedagem depende,

Revista Acadêmica Observatório de Inovação do Turismo, v. 15, n. 2, agosto/2021 


\section{POUSADA DO SANDI, PARATY-RJ.}

quase que por completo, da atuação dos colaboradores. Justamente por isso, estes indivíduos devem ser compreendidos como o principal capital organizacional (WALKER, 2002; ESTEBAN-LLORET; ARAGÓN-SÁNCHEZ; CARRASCO-HERNÁNDEZ, 2014). Em razão disso, precisam possuir um alto nível de qualificação para que assim possam prover melhores resultados, desempenhos e diferenciais competitivos às suas organizações (SANTOS; SILVA, 2015), prospectando valor agregado à imagem de seus estabelecimentos.

\section{Metodologia}

O estudo de caso evidencia-se como um importante instrumento analítico que permite dar maior credibilidade, veracidade e tenacidade às pesquisas contemporâneas (SINGLETON JR.; STRAITS, 2010). Afinal de contas, seu intuito é propiciar uma investigação empírica cuja finalidade é oferecer informações mais precisas e detalhadas (YIN, 2005; GIL, 2009) que possibilitem a construção de uma análise descritiva ou explicativa de um determinado objeto frente à sua atual realidade (BRUYNE; HERMAN; SCHOUTHEETE, 1991).

Por causa disso, esta pesquisa assumiu um caráter descritivo a partir do momento em que buscou ilustrar as reais características/especificidades de seu objeto (VEAL, 2011), preocupando-se em compreender o estabelecimento das variáveis que culminam (GIL, 2009) na realidade organizacional investigada. Dessa maneira, os autores deste trabalho se valeram dos pressupostos da análise mista, procedimento que vem obtendo gradativa robustez nos últimos 20 anos (ROBSON, 2011) por assegurar resultados mais plenos e elucidativos (HAIR JR. et al., 2009), pautada por preceitos quanti-qualitativos que propiciaram um entendimento mais amplo de sua problemática, permitindo a exposição de discussões mais confiáveis e assertivas (HAIR JR. et al., 2009; ROBSON, 2011).

Assim, pelo viés quantitativo, este estudo teve o intuito de obter, por meio de dados numéricos, informações capazes de garantir uma maior precisão, evitando quaisquer tipos de distorções acerca dos resultados que tangenciam a temática investigada (CRESWELL, 2003). Não obstante, sua estruturação deu-se a partir de um questionário em escala tipo Likert de 07 pontas $-07=$ Excelente, $06=$ Muito Bom, 05 = Bom, 04 = Nem Bom / Nem Ruim, 03 = Regular, 02 = Péssimo, 01 = Não sei responder - aplicado junto aos colaboradores que atuam nos setores operacionais da Pousada do Sandi. Ainda sobre este instrumento, suas perguntas buscaram: (1) identificar o perfil do(a) respondente; (2) aferir o nível de frequência, qualidade e grau de participação dos colaboradores e chefias diretas nas atividades de capacitação e treinamento; (3) compreender o elo entre as práticas de treinamento e as necessidades operacionais do estabelecimento investigado; (4) discutir a funcionalidade/resultado dos programas de 
treinamento sobre os departamentos hoteleiros; (5) apreender a percepção da eficácia dessas ações sobre o dia a dia operacional do empreendimento.

Através deste instrumento, mensurou-se possíveis vantagens ou desvantagens que as práticas de treinamento exerciam sobre a operacionalização deste meio de hospedagem. Assim sendo, 13 funcionários - sendo 5 do departamento de recepção e 8 do de governança - responderam este instrumento ao final do segundo semestre de 2017. Sobre o número de respondentes, há de se destacar os seguintes fatos:

- a amostragem aplicada foi a probabilística de caráter simples;

- o quantitativo alcançado representa $48,15 \%$ do total de funcionários que atuam em áreas operacionais nesta pousada. Atualmente, o estabelecimento conta com 33 colaboradores, dos quais 27 atuam no setor operacional e 06 são gestores departamentais departamento;

- os departamentos de recepção e de governança são vitais à qualidade das operações hoteleiras (CÂNDIDO, 2001; CASTELLI, 2005; MINCIOTTI; SANTOLIA; KASPAR, 2008). Dito isso, a plena adesão de todos esses funcionários dá uma maior credibilidade aos resultados aqui evidenciados.

Por fim, o tratamento dos dados quantitativos seguiu os preceitos descritivos, ilustrados por frequências e porcentagens. Já pelo viés qualitativo, Miles, Huberman e Saldaña (2014) exaltaram sua capacidade de traduzir e interpretar a realidade como um todo a partir dos fenômenos observados no local, contribuindo para reduzir a distância entre a realidade e a teoria. Para a consolidação deste viés, os autores optaram por entrevistar - em outubro de 2017, por 02h:37min de gravação, com o auxílio de um roteiro semiestruturado - a gerente geral do estabelecimento pesquisado. A escolha deste perfil se deu pelo fato de este ser "a variável humana mais importante a afetar a receita de um hotel a curto prazo" (HAYES; NINEMEIER, 2005, p. 29). Justamente por isso, esse profissional deve mensurar, de maneira contínua, o nível de eficiência de sua equipe.

Posto isso, para a condução desta entrevista, os autores optaram pela técnica "entrevista em profundidade", pelo fato de esta propiciar um melhor entendimento do tema através de perguntas que buscaram abstrair, da participante, um maior número possível de informações/detalhes sobre o objeto investigado (ARDIGÓ; CAETANO; DAMO, 2016).

Não obstante, com relação ao roteiro supracitado, suas perguntas intencionaram: (1) reconhecer a percepção do gestor sobre a importância e as implicações das políticas de treinamento em sua organização; (2) discutir a frequência e o perfil dos participantes destas atividades; (3) entender os tipos de avaliação criados para discernir o grau de efetividade destes programas; (4) identificar as implicações dos treinamentos sobre a qualidade, os resultados e a imagem da organização investigada.

Revista Acadêmica Observatório de Inovação do Turismo, v. 15, n. 2, agosto/2021 
Explicitada todas essas particularidades, os dados qualitativos foram tratados observando-se os preceitos de Bardin, "seguindo as orientações de pré-análise, exploração do conteúdo das entrevistas e, por fim, a interpretação e a prospecção dos resultados" (SANTOS; ALMEIDA; MIRANDA, 2021, p. 197).

E, por fim, buscou-se compreender a percepção dos hóspedes acerca da qualidade das operações hoteleiras ali executadas. A ideia, a priori, era mensurar seus respectivos graus de satisfação, estabelecendo um paralelo com as ações de treinamento e desenvolvimento orquestradas nesta pousada. Assim, tal intuito foi efetuado a partir das avaliações ofertadas pela TripAdvisor, Booking.com, Kayak e Expedia, plataformas que vêm mudando, nos últimos anos, a maneira como os turistas contemporâneos planejam suas viagens (FILIERI; ALGUEZAUI; MCLEAY, 2015).

\section{Resultados e Discussão}

A Pousada do Sandi, localizada na região Costa Verde do Estado do Rio de Janeiro, é tida como um dos empreendimentos hoteleiros mais luxuosos e tradicionais do município de Paraty, possuindo notório reconhecimento graças às características de sua arquitetura, design e elementos decorativos que remetem à época do Brasil Colônia (Figura 3), bem como pela qualidade de seus produtos, serviços e atendimentos (ASSOCIAÇÃO DE HOTÉIS ROTEIROS DE CHARME, s/d).

Quadro 1 - Pousada do Sandi. Ficha Técnica

\begin{tabular}{|c|c|}
\hline 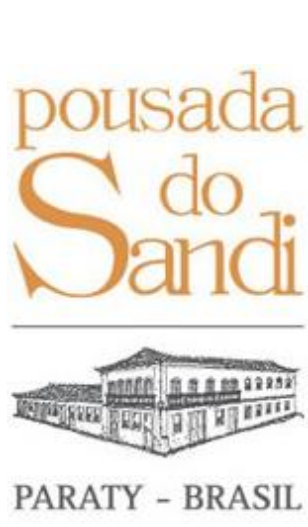 & $\begin{array}{l}\text { Localização: Rua Largo do Rosário, } \mathrm{n}^{\circ} 01 \text { - Bairro - Centro Histórico - Paraty-RJ } \\
\text { Inauguração: Ano de } 1987 \\
\text { Tipo de Administração: Modelo de gestão compartilhado } \\
\text { Principal Segmento: Hotelaria de Luxo } \\
\text { Classificação: } 05 \text { Estrelas } \\
\text { Missão: Superar expectativas, oferecendo serviços consistentes e de alta qualidade, } \\
\text { fidelizando, assim, os clientes. } \\
\text { Visão: Ser reconhecido como um dos líderes no segmento hoteleiro de luxo pela } \\
\text { excelência dos serviços prestados. } \\
\text { Principais Valores Organizacionais: A valorização do indivíduo para a obtenção de } \\
\text { melhores resultados para a equipe e para a empresa. Justiça e ética em todos os } \\
\text { relacionamentos interpessoais. }\end{array}$ \\
\hline \multicolumn{2}{|l|}{ ESTRUTURA } \\
\hline \multicolumn{2}{|c|}{$\begin{array}{l}\text { Unidades Habitacionais: } 25 \text { UH'S } \\
\text { Salas de Eventos: } 01 \text { salão para pequenos eventos e convenções com capacidade máxima de } 30 \text { pessoas. } \\
\text { Estrutura para Lazer: Mini Spa, academia, jardim e jacuzzi } \\
\text { Estrutura A\&B: } 02 \text { restaurantes e } 01 \text { bar, room service. } \\
\text { Site: https://www.pousadadosandi.com.br }\end{array}$} \\
\hline
\end{tabular}

Fonte: Elaborado pelos autores

Ademais, tal distinção também se deve aos seguintes fatores: sua localização privilegiada, as especificidades de seus serviços e seus valores organizacionais (Quadro 1). Posto isso, a escolha dessa 
TREINAMENTO E EXCELÊNCIA

ORGANIZACIONAL: UM ESTUDO DE CASO NA

POUSADA DO SANDI, PARATY-RJ.
Rodrigo Amado dos Santos Patrícia da Silva Jorge

empresa também foi influenciada pelo caráter empreendedor de seus gestores. Afinal de contas, desde a década de 1980 - período de sua fundação - esse meio de hospedagem se destaca pelo fortalecimento da vocação turística de sua localidade, bem como pela inovação dos produtos e serviços hoteleiros ofertados nesta destinação (LENZIARDI, 2011).

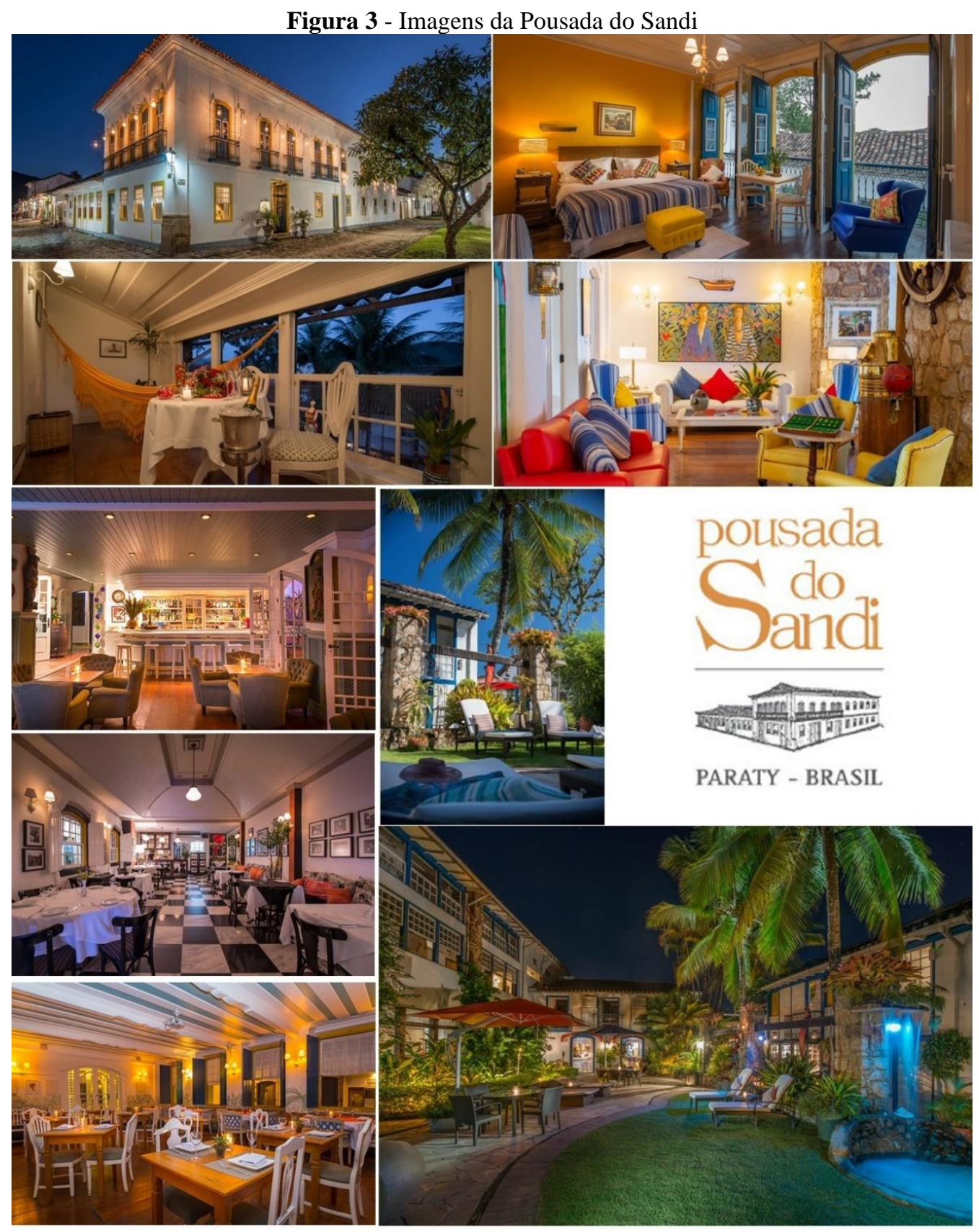

Fonte: Imagens captadas na Internet (Booking.com)

Sobre sua estrutura organizacional, a Figura 4 expõe as divisões hierárquicas executadas por 33 colaboradores, dos quais 06 são gestores e 27 atuam na área operacional.

Revista Acadêmica Observatório de Inovação do Turismo, v. 15, n. 2, agosto/2021 
Figura 4 - Organograma Organizacional - Pousada do Sandi

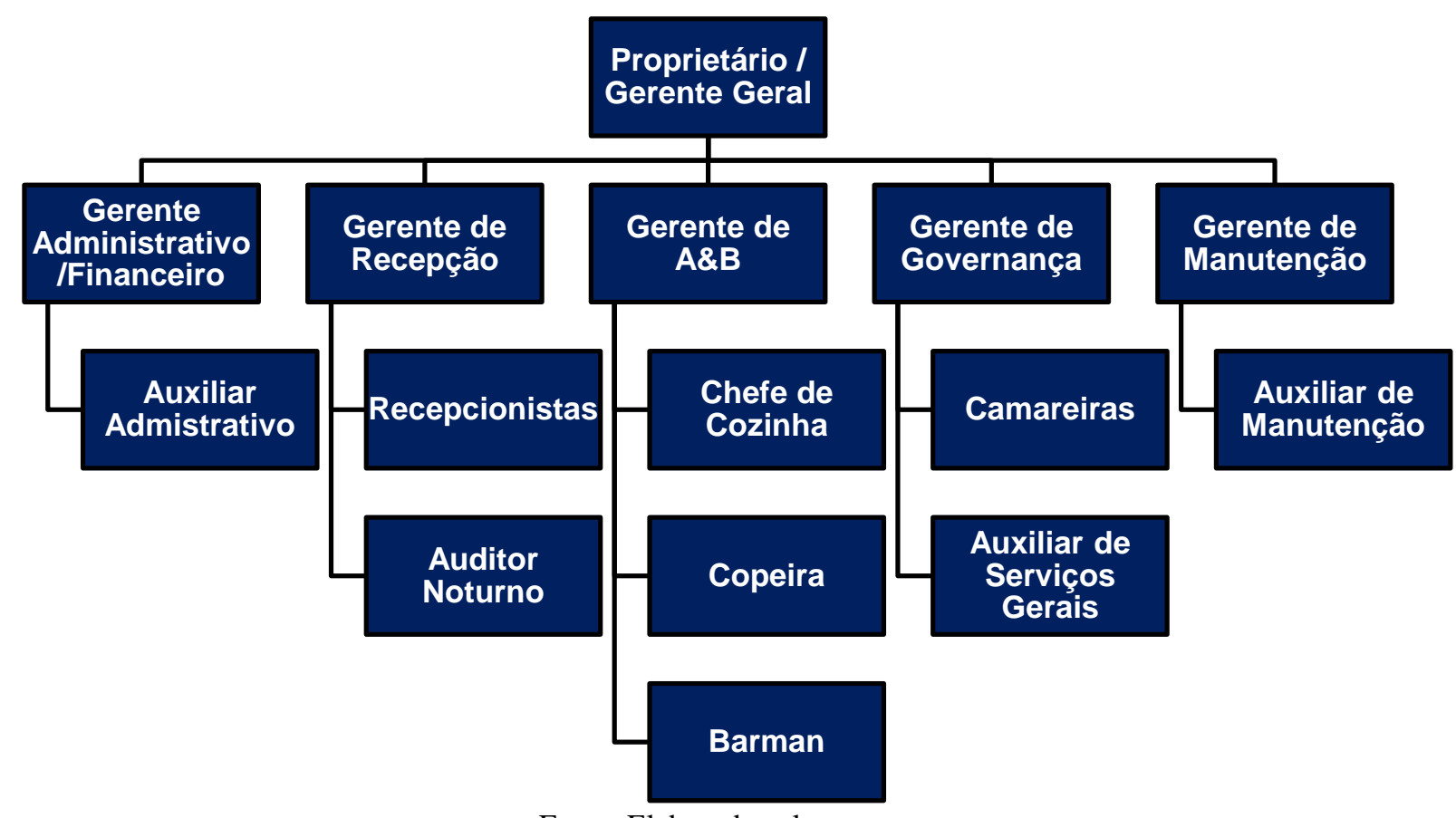

Fonte: Elaborada pelos autores.

Por meio deste organograma, as atividades operacionais da Pousada do Sandi são apontadas. Sobre essas, Hayes e Ninemeier (2005) afirmam que as operações hoteleiras são executadas de formas distintas, a depender das características de sua localidade, da classificação, porte e segmento de atuação do empreendimento, bem como das idiossincrasias de seus setores.

Justamente por isso, demandam planos setoriais que observem as especificidades de seus produtos, processos e quantificações para que as expectativas, necessidades e preferências de seus consumidores sejam plenamente alcançadas (ROBLEDO; ARÁN; PÉREZ-ARANDA, 2015; SANTOS; SILVA, 2015). Nesse sentido, sobre os setores retratados na Figura 02, durante sua entrevista, a gerente geral salientou as seguintes responsabilidades:

- Setor Administrativo/Financeiro: estabelecer um exímio controle sobre os processos de compras, de almoxarifado, de contabilidade fiscal e gerencial.

- Setor de Recepção: desenvolver a política tarifaria; definir os parâmetros de qualidade de suas ações operacionais; estabelecer os esquemas de folga de seus funcionários.

- Setor de Alimentos e Bebidas: propor o design e o conceito de seus restaurantes e bares; determinar o quadro de pessoal; quantificar e tipificar seus enxovais; criar a engenharia de cardápios; estabelecer horários de funcionamento, esquemas de folga e triagem (recebimento e armazenamento) de seus insumos.

Revista Acadêmica Observatório de Inovação do Turismo, v. 15, n. 2, agosto/2021 
- Setor de Governança: determinar a quantidade de enxoval, comodidades das UH's, os esquemas de folgas e as logísticas operacionais de limpeza; equacionar os trâmites para a supervisão dos serviços de limpeza das UH's e áreas sociais.

Com relação à qualidade de seus serviços, o quadro 2 expõe um conjunto de avaliações que exprime os graus de satisfação de seus hóspedes. Para essa tarefa, foram utilizadas as análises das seguintes plataformas: Booking.com; Expedia; Kayak; e TripAdvisor. Estas foram escolhidas por possuírem um papel decisivo na escolha dos serviços turísticos contemporâneos, visto que oferecem um amplo leque de informações que auxiliará o(a) turista moderno(a) na definição de quais produtos ou serviços este(a) consumirá (RUS; NEGRUSA, 2014).

Quadro 2 - Grau de satisfação dos hóspedes.

\begin{tabular}{|c|c|c|}
\hline \multirow{2}{*}{ Booking.com } & $\begin{array}{l}\text { Data de análise: } 31 \text { de outubro de } 2017 \\
\text { Quantidade de respondentes: } 400 \\
9,4 \text { localização } \\
9,3 \text { funcionários } \\
9,1 \text { de limpeza do quarto } \\
\text { 9,0 conforto }\end{array}$ & $\begin{array}{l}8,7 \text { comodidades } \\
8,2 \mathrm{Wi}-\mathrm{Fi} \text { gratuito } \\
7,9 \text { custo benefício }\end{array}$ \\
\hline & $\begin{array}{l}\text { Data de análise: } 01 \text { de março de } 2020 \\
\text { Quantidade de respondentes: } 563 \\
9,7 \text { localização } \\
9,4 \text { funcionários } \\
9,1 \text { de limpeza do quarto } \\
9,0 \text { conforto }\end{array}$ & $\begin{array}{l}8,9 \text { comodidades } \\
7,9 \text { custo benefício } \\
7,7 \text { Wi-Fi gratuito }\end{array}$ \\
\hline \multirow{2}{*}{$\underline{\text { Expedia }}$} & $\begin{array}{l}\text { Data de análise: } 31 \text { de outubro de } 2017 \\
\text { Quantidade de respondentes: } 125 \\
76 \% \text { dos Hóspedes Recomendam } \\
4,3 \text { de } 5 .\end{array}$ & $\begin{array}{l}\text { 4,5 de Serviço de Equipe } \\
\text { 4,4 de Limpeza de Quarto } \\
\text { 4,2 de Condição do Hotel } \\
\text { 4,1 de Conforto do Quarto }\end{array}$ \\
\hline & $\begin{array}{l}\text { Data de análise: } 01 \text { de março de } 2020 \\
\text { Quantidade de respondentes: } 173 \\
4,4 \text { de } 5 \text { - Excelente }\end{array}$ & $\begin{array}{l}\text { 4,5 de Serviço e Funcionário } \\
\text { 4,5 de Comodidades } \\
\text { 4,4 de Limpeza } \\
\text { 4,3 de Condição do Hotel }\end{array}$ \\
\hline$\underline{\text { Kayak }}$ & $\begin{array}{l}\text { Data de análise: } 31 \text { de outubro de } 2017 \\
\text { Quantidade de respondentes: } 479\end{array}$ & $\begin{array}{l}\text { Comodidades }-10 \\
\text { Café da manhã }-9,6 \\
\text { Localização }-9,4 \\
\text { Serviço }-9,2 \\
\text { Atmosfera }-8,8 \\
\text { Conforto - } 6,3 \\
\text { Quarto - 6,1 } \\
\text { Custo Benefício - 4,4 } \\
\text { Internet - 2,0 } \\
\end{array}$ \\
\hline
\end{tabular}

Revista Acadêmica Observatório de Inovação do Turismo, v. 15, n. 2, agosto/2021 


\begin{tabular}{|c|c|c|}
\hline & $\begin{array}{l}\text { Data de análise: } 01 \text { de março de } 2020 \\
\text { Quantidade de respondentes: } 825 \\
\text { Avaliação Geral }-9,0 \text { de } 10 \\
\text { Excelente }\end{array}$ & $\begin{array}{l}\text { Café da manhã - 9,5 } \\
\text { Localização - 9,1 } \\
\text { Serviço - 9,1 } \\
\text { Comodidades - 9,0 } \\
\text { Comida - 9,0 } \\
\text { Comodidades - 9,0 } \\
\text { Limpeza }-5,1\end{array}$ \\
\hline \multirow{2}{*}{$\underline{\text { TripAdvisor }}$} & $\begin{array}{l}\text { Data de análise: } 31 \text { de outubro de } 2017 \\
\text { Quantidade de respondentes: } 536 \\
\text { 53\% Excelente } \\
\text { 36\% Muito Bom } \\
8 \% \text { Razoável }\end{array}$ & $\begin{array}{l}2 \% \text { Ruim } \\
1 \% \text { Horrível }\end{array}$ \\
\hline & $\begin{array}{l}\text { Data de análise: } 01 \text { de março de } 2020 \\
\text { Quantidade de respondentes: } 703 \\
\text { 55,19\% Excelente } \\
\text { 33,14\% Muito Bom } \\
7,25 \% \text { Razoável }\end{array}$ & $\begin{array}{l}2,13 \% \text { Ruim } \\
2,27 \% \text { Horrível }\end{array}$ \\
\hline
\end{tabular}

Fonte: Booking.com (2017); Expedia (2017); Kayak (2017); TripAdvisor (2017); Booking.com (2020); Expedia (2020); Kayak (2020); TripAdvisor (2020). Elaborado pelos autores.

Para uma melhor compreensão do Quadro 02, uma explicação necessita ser apresentada: a escolha do eixo temporal. Os anos de 2017 e 2020 foram eleitos pelos seguintes motivos: o final de 2017 representa o marco temporal em que as entrevistas e questionários foram aplicados junto aos clientes internos do estabelecimento investigado. Justamente por isso, a percepção dos hóspedes deve ser entendida como um relevante complemento aos dados quanti-qualitativos ali exaltados. Afinal, são suas avaliações que determinam os níveis de sucesso e fracasso das estratégias organizacionais (BRANCO; RIBEIRO; TINOCO, 2010).

Já o ano de 2020 marca o período de submissão desta pesquisa. Mas, para além disso, deve ser visto como um importante contraponto, que permite observar se as métricas de qualidade continuaram ou não sendo bem valoradas pelos consumidores desta pousada. Logo, os Gráficos 01 e 02 externam possíveis avanços, estagnações e/ou retrocessos visualizados nas plataformas Booking.com e Expedia:

Gráfico 1 - Contraponto das avaliações entre os anos de 2017 e 2020 - Booking.com. 


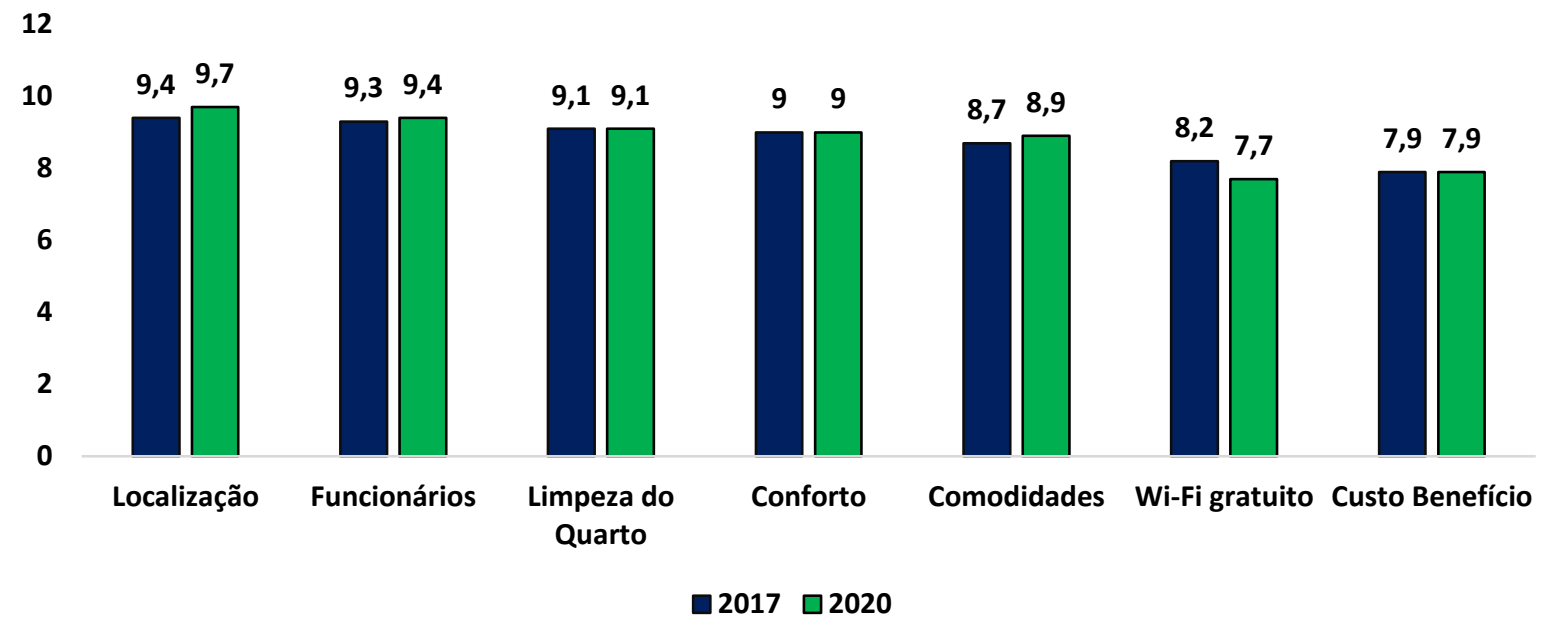

Fonte: Elaborado pelos autores.

Através desses dados tornou-se possível ponderar que três variáveis - "localização", "funcionários" e "comodidades" - experimentaram, respectivamente, as seguintes taxas de crescimento: $3,19 \%, 1,08 \% ; 2,30 \%$. A priori, esses números podem não ser tão expressivos. No entanto, quando se observa o número de respondentes - em 2017 foram 400; em 2020, 563 - este avanço ganha outra conotação. Afinal, 163 novos clientes apresentaram avaliações que permitem dizer que as métricas de qualidade que sustentam estes escopos analíticos ainda continuam sendo bem empregadas. O mesmo vale para "limpeza de quarto", "conforto" e "custo benefício", que se mantiveram no mesmo nível. Todavia, a variável "Wi-Fi Gratuito" foi a única que experimentou um decréscimo na ordem de 6,10\%.

Gráfico 2 - Contraponto das avaliações entre os anos de 2017 e 2020 - Expedia.

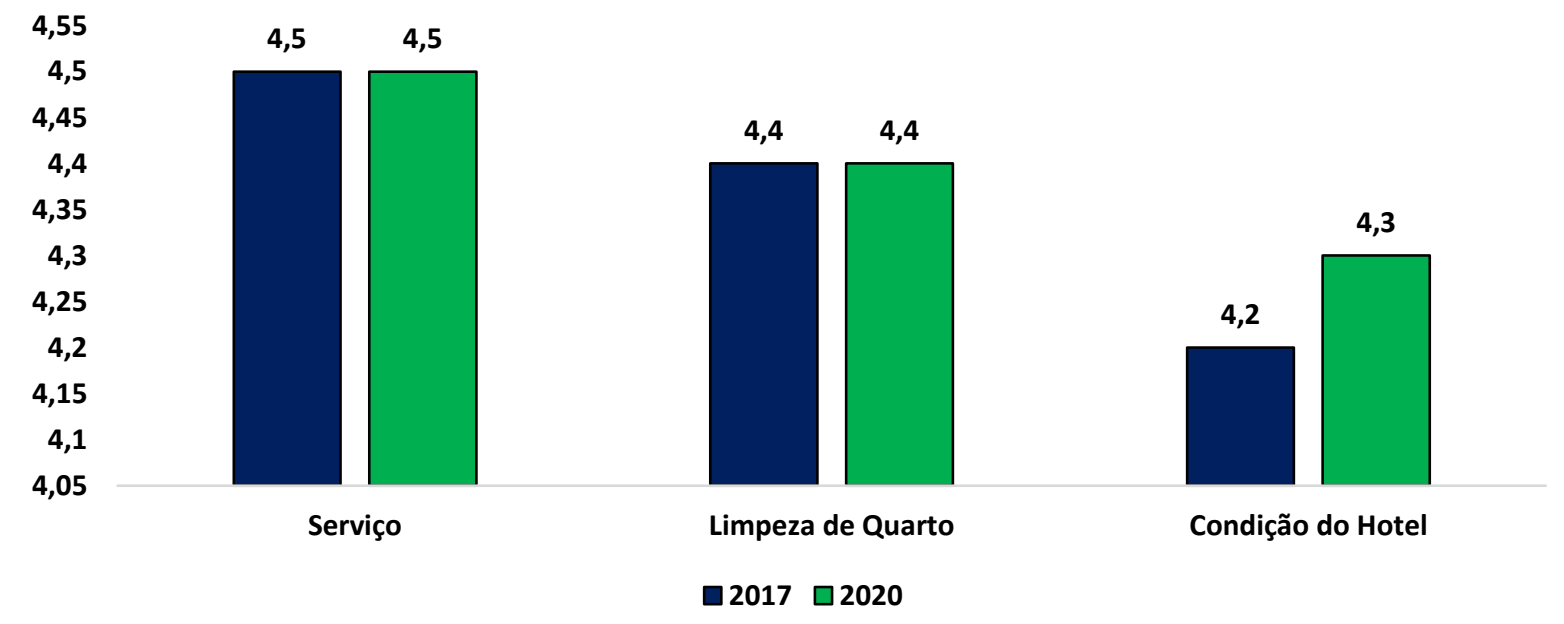

Fonte: Elaborado pelos autores.

Nesta plataforma, as variáveis "serviço" e "limpeza de quarto" se mantiveram estagnadas. E tal qual dito anteriormente, isso necessariamente não significa algo ruim. Principalmente se compararmos 
o número de respondentes que, em 2017 foram 125 e em 2020, 173. Através destas 48 novas avaliações, é possível ponderar que as estratégias aplicadas continuaram gerando o mesmo efeito de excelência sobre as métricas de "serviço" e "limpeza de quarto". Não obstante, a "condição do hotel" ainda experimentou uma valoração de 2,38\%. Com relação à plataforma Kayak, apesar de suas variáveis transparecerem um ligeiro declínio entre 2017 a 2020, o número total de respondentes neste período observou um crescimento de 72,23\%, saindo de uma avaliação geral de 8,9 (2017) para 9,0 (2020). Já na plataforma TripAdvisor, o aumento de respondentes foi de $31,16 \%$, além de se manter a descrição de um cenário positivo.

Por meio deste panorama, existe a possibilidade de se ponderar que as métricas positivas de avaliação foram mantidas e os proprietários e gestores da Pousada do Sandi buscaram zelar pela qualidade de seus serviços, de forma a garantir um exímio grau de conforto, bem-estar e acolhimento para seus hóspedes. Indiretamente, o escopo analítico do Quadro 2 transparece eloquentes resultados, provenientes das políticas de treinamento e qualificação - vistas como mecanismos importantes para que os serviços desempenhados sejam, ao menos, satisfatórios para o cliente (SANTOS; SILVA, 2015).

Apesar de esta pousada não possuir - conforme aponta sua gerente geral - um setor responsável por seus processos de qualificação, seus gestores departamentais acumulam essa função, tornando-se responsáveis por selecionar, orientar, qualificar e lapidar seus colaboradores. Isso é algo que já se inicia no primeiro contato dos novos funcionários, por meio do treinamento On the Job. Sucintamente, esse procedimento é descrito pela gerente geral enquanto uma orientação que dura aproximadamente 30 dias e que explicita valores, missão e visão organizacional, bem como os deveres e atribuições desses novos colaboradores acerca das operações e particularidades de seus departamentos.

Decerto, esta prática realça, de forma muito mais eficiente, as habilidades e competências necessárias para a execução das tarefas que serão incumbidas aos novos integrantes (SANTOS et al., 2013). No entanto, para que isso ocorra, Boog (2013) ressalta a necessidade da participação do(a) supervisor(a) da área qualificada. Afinal de contas, como aponta o referido autor, este supervisor(a) será responsável por identificar as reais necessidades de seu setor, equalizando-as de maneira mais assertiva durante esta etapa de qualificação.

Não obstante, a Pousada do Sandi também conta com a parceria da Associação de Hotéis Roteiros de Charme para promover o aperfeiçoamento de seus colaboradores. Através dessa cooperação, anualmente são oferecidos treinamentos que promovem a reciclagem de conhecimentos, técnicas, competências e habilidades frente às tendências e oportunidades do mercado hoteleiro de luxo.

Explicitada esta descrição preliminar, reitera-se que o objetivo dessa pesquisa foi expor a importância/contribuição que as capacitações assumem perante os desempenhos organizacionais, de maneira que os gestores hoteleiros as percebam como um importante diferencial competitivo. Para tal 
proposta, um questionário semiestruturado foi respondido por 13 colaboradores da área operacional da Pousada do Sandi. Acerca de seus perfis, observou-se os seguintes delineamentos: faixa etária - 46\% possui entre 31 a 40 anos e 54\% está na faixa etária de 41 a 50 anos de idade; escolaridade - $54 \%$ possui o ensino fundamental, $38 \%$ o ensino médio e $08 \%$ o ensino superior incompleto.

Em relação à composição desse questionário, os seguintes temas foram abordados: frequência e qualidade dos treinamentos; grau de participação e envolvimento de colaboradores e de chefias diretas; e o atendimento das necessidades operacionais/gerenciais dessa pousada.

Sobre a frequência dos treinamentos, $100 \%$ dos respondentes a consideram como "Boa", o que remente a uma margem de aprimoramento para esse quesito. Afinal de contas, as escalas "Muito Bom" ou "Excelente" poderiam ter sido demarcadas. Ademais, quanto maior for a frequência e o nível de instruções dados aos colaboradores, melhor será a possibilidade de se ofertar informações e conhecimentos condizentes a uma realidade mercadológica e organizacional que se encontram em constante transformação (ARAGÓN-SÁNCHEZ; BARBA-ARAGÓN; SANZ-VALLE, 2003; GHEBREGIORGIS; KARSTEN, 2007; ESTEBAN-LLORET; ARAGÓN-SÁNCHEZ; CARRASCOHERNÁNDEZ, 2014; UBEDA-GARCIA et al., 2014), como é o caso do mercado hoteleiro.

Nesse sentido, o treinamento "prepara o potencial humano frente às inovações tecnológicas e as constantes mudanças do mercado de trabalho" (GOMES; TEODORO, 2010, p. 24) e, em vista disso, pleiteia o desenvolvimento contínuo e ininterrupto dos princípios da excelência nas condutas de seus participantes. E como resultado, espera-se que a questão da qualidade seja um dos elementos característicos à imagem organizacional. Exatamente como se pôde observar no Quadro 2 deste estudo.

Dito isso, em específico à qualidade de seus treinamentos, a percepção dos entrevistados foi assim descrita: 15,38\% - Excelente; 84,62\% - Bom. Uma perspectiva que transparece outra oportunidade de melhoria. Tendo em conta que esse parâmetro deve contemplar planificações que garantam um melhor e maior desempenho dos colaboradores (FU; YANG; CHU, 2014), evidencia-se aqui a oportunidade de aprimorar os relacionamentos interpessoais dessa pousada, visto que estes influenciam não só a qualidade, como também os próprios resultados organizacionais (ROBLEDO; ARÁN; PÉREZARANDA, 2015). Nesta perspectiva, tal premissa deve ser vista como condição substancial à maximização da eficácia, eficiência, assertividade e produtividade de uma organização hoteleira.

De mais a mais, conforme já destacado ao longo deste trabalho, os colaboradores devem ser vistos como um dos principais elementos para se gerar vantagens competitivas em um meio de hospedagem (ESTEBAN-LLORET; ARAGÓN-SÁNCHEZ; CARRASCO-HERNÁNDEZ, 2014). Não obstante, será por meio de suas singularidades que o sucesso dessas organizações será alcançado. Assim, tais profissionais precisam ser bem qualificados e estarem dispostos a fazer parte do futuro de suas

Revista Acadêmica Observatório de Inovação do Turismo, v. 15, n. 2, agosto/2021 
empresas. Dito isso, torna-se primordial mensurar o grau de participação e envolvimento desses profissionais nas ações de qualificação da Pousada do Sandi.

Ao indagar os respondentes sobre este assunto, uma resposta foi uníssona: 100\% dos participantes avaliaram este quesito como "Bom". Contudo, para que esta participação atinja o patamar "Excelente", destaca-se a importância das políticas de treinamento cativarem e instigarem a presença de todos os trabalhadores - independentemente de suas hierarquias e cargos - contemplando e atendendo suas reais necessidades.

Nesse contexto, Ubeda-García et al. (2014) e Robledo, Arán e Pérez-Aranda (2015) afirmam a necessidade de se expor atributos, papéis e lógicas que estimulem os trabalhadores a galgarem novas competências, técnicas, conhecimentos e habilidades para que, a partir disso, sejam capazes de ascender em suas corporações.

Por conseguinte, assim como os colaboradores têm um papel primordial para o crescimento e desenvolvimento organizacional, a figura do líder se evidencia como a "chave" para que essa prosperidade ocorra. Deste modo, caberá ao líder incentivar, influenciar e motivar suas equipes para que os objetivos e metas empresariais sejam cumpridos (PEREIRA; LUCENA, 2008). Além disso, essas figuras devem assumir posturas, atitudes e condutas mais proativas (HAYES; NINEMEIER, 2005), visto que suas participações nas ações de treinamento poderão influenciar os demais a assumir esse mesmo compromisso.

Assim, com relação ao grau de participação e envolvimento das chefias da Pousada do Sandi nas ações de qualificação, os respondentes expuseram o seguinte posicionamento: 15,38\% - Excelente; $84,62 \%$ - Bom. Uma perspectiva melhor que a dos colaboradores, mas que também revela uma oportunidade de aperfeiçoamento. Em especial, se as metas propostas pelas qualificações forem consideradas. Para que essas sejam as mais coerentes possíveis, tais sujeitos devem estabelecer estratégias que contribuam para motivação, confiança e cumplicidade de seus liderados, bem como atendam aos interesses organizacionais.

Já no tocante à assertividade dessas capacitações, houve a preocupação de se mensurar a forma como contemplavam as necessidades e especificidades operacionais desse ambiente hoteleiro. Dito isso, $54 \%$ dos respondentes avaliaram este quesito como "Excelente". Os outros $46 \%$ identificaram-no como "Bom".

Nota-se que estes posicionamentos enfatizam que tais práticas, a priori, são bem idealizadas e coerentes com as necessidades deste meio de hospedagem. Contudo, também exprimem uma margem que oportuniza uma melhoria, que poderia ser alcançada através dos seguintes questionamentos diretivos (TEIXEIRA, 2011; SANTOS; SILVA, 2015; SOUZA, 2017; LIMA; SILVA, 2018):

- O que deve ser ensinado?

Revista Acadêmica Observatório de Inovação do Turismo, v. 15, n. 2, agosto/2021 
- Quem deve passar por esta aprendizagem?

- Quais métricas balizarão este processo?

- Qual será o papel dos instrutores e dos participantes?

- Quais serão os indicadores que retroalimentarão este processo?

- De que forma esta prática estará conectada às tendências e oportunidades de seu mercado?

De acordo com a gerente geral, após cada qualificação são utilizados indicadores para se medir o grau de satisfação dos participantes e, posteriormente, dos próprios hóspedes, de maneira que os resultados operacionais possam ser devidamente aferidos e aprimorados.

Em específico ao feedback dos colaboradores, este é realizado durante as reuniões setoriais. Estas expõem críticas, elogios e sugestões para a melhoria do trabalho em equipe. Já pelo ponto de vista do hóspede, duas métricas são empregadas. A primeira diz respeito à pesquisa de satisfação executada ao término da hospedagem. A segunda contempla o acompanhamento das avaliações que tais consumidores fazem em sites como TripAdvisor e Booking.com.

A partir dessas contextualizações, novas propostas de capacitação são criadas no intuito de se maximizar os resultados das práticas de qualificação da Pousada do Sandi. Por conseguinte, ponderouse o fato de que há uma necessidade de se estabelecer um planejamento mais sistêmico que avalie, contínua e progressivamente, os possíveis gaps operacionais, as tendências e oportunidades de seu mercado (CAON; CORREAA, 2016).

Desse modo, considera-se a ferramenta $5 \mathrm{~W} 2 \mathrm{H}$ como um instrumento pertinente, visto que oferece uma definição mais clara sobre ações, sujeitos e procedimentos necessários (Quadro 3) para que os processos organizacionais sejam mais bem elaborados e integralizados às suas respectivas realidades (SEIFFERT, 2013).

Com base nesses questionamentos, uma das propostas sugeridas estaria vinculada ao desenvolvimento de dinâmicas em grupo, que teriam os gestores departamentais como seus responsáveis. Essas dinâmicas seriam desenvolvidas por meio de teatralizações ou estudos de caso que possibilitariam a exposição de métricas operacionais bem sucedidas e, por meio destas, o estabelecimento de um know how válido, coerente e verossímil aos seus participantes (SANTOS; SILVA, 2015).

Quadro 3 - Preceitos da 5W2H

\begin{tabular}{|c|l|}
\hline PRECEITOS & SIGNIFICADOS \\
\hline$W H A T$ & $\begin{array}{l}\text { O que será feito? Quais são suas características e especificidades? Quais são os } \\
\text { objetivos a serem alcançados? }\end{array}$ \\
\hline$W H O$ & Quem conduzirá o plano de ação? Quem participará? \\
\hline$W H E R E$ & Onde será executada a ação? \\
\hline$W H E N$ & Quando será executada? \\
\hline
\end{tabular}

Revista Acadêmica Observatório de Inovação do Turismo, v. 15, n. 2, agosto/2021 
POUSADA DO SANDI, PARATY-RJ.

\begin{tabular}{|c|l|}
\hline WHY & Por que será executada? \\
\hline$H O W$ & Como será executada? \\
\hline HOW MUCH & Quanto custa para executar a ação? \\
\hline
\end{tabular}

Fonte: Seiffert (2013). Adaptado pelos autores.

Sob a égide da dramatização de situações corriqueiras, a equipe buscaria soluções mais adequadas aos problemas encenados, sempre contemplando as necessidades dos envolvidos. Já pelo viés do estudo de caso, cada gestor ofereceria uma situação problema, conforme as especificidades de seus setores. Ao final de um tempo estipulado, cada participante deveria apresentar suas soluções, discutindo com os demais o grau de suas assertividades.

Ademais, a construção de um sistema de rodízio habitual entre os colaboradores seria algo demasiadamente válido. Com essa proposta, cada funcionário entenderia as especificidades e desafios que se passam em outras rotinas operacionais, observando como essas são, por exemplo, negativamente influenciadas por uma comunicação organizacional falha. Tal proposta fortaleceria o espírito de equipe, propiciando uma maior compreensão sobre as complexidades e interdependências observadas em um empreendimento hoteleiro contemporâneo que prima por elevados padrões de qualidade e excelência organizacional.

Um aspecto pertinente a se destacar é que tais propostas não necessitariam de custos vultuosos para suas operacionalizações. Para os seus desenvolvimentos, há de se contar com a proatividade, criatividade e um amplo conhecimento mercadológico de seus idealizadores.

\section{Considerações Finais}

O treinamento deve ser visto como questão primordial para o desempenho organizacional. Por meio de suas práticas regulares, os empreendimentos hoteleiros serão capazes de alcançar seus objetivos e metas, contribuindo para o seu crescimento frente às complexidades e exigências do mundo globalizado.

Ao longo destas narrativas foi possível evidenciar a influência positiva que o treinamento organizacional acarreta sobre os resultados operacionais de um meio de hospedagem. Nesse sentido, esses procedimentos buscam a valorização do capital humano, a melhoria da qualidade dos relacionamentos interpessoais e a exposição de uma via capaz de atender às expectativas da empresa, dos colaboradores e dos hóspedes.

De maneira geral, crê-se que o objetivo da pesquisa foi atingido. Pôde-se observar que as práticas de treinamento influenciam diretamente o nível da qualidade dos serviços ofertados, exercendo peso significativo sobre os resultados operacionais do meio de hospedagem investigado. Prova disso 
reside no reconhecimento de seus clientes acerca do comprometimento e nível de excelência ofertados durante suas hospedagens (e que fora devidamente retratado neste estudo), além de sua representatividade e destaque perante os demais meios de hospedagem que compõem o mercado de sua região.

Já sobre o questionamento desta pesquisa - de que maneira os programas de treinamento influenciam a qualidade, os resultados e a imagem do meio de hospedagem investigado? - observou-se que as políticas de treinamento visam lapidar conhecimentos, técnicas, habilidades e competências dos indivíduos, de maneira que estes desempenhem melhor suas funções.

Tal prerrogativa sem dúvida contribui para a qualidade dos serviços/produtos ofertados em um meio de hospedagem, refletindo positivamente no grau de satisfação do cliente final. Em específico ao estudo de caso realizado na Pousada do Sandi, percebeu-se que apesar do estabelecimento não possuir um setor específico para treinar e qualificar os colaboradores - como pode ser visto, por exemplo, em empresas hoteleiras de grande porte - os gestores departamentais acumulam tais funções e, em específico, a qualidade de suas operações alcançam bons resultados.

Através dos argumentos até aqui expostos reitera-se que as práticas de treinamento organizacional atuam como princípio básico para a construção de vantagens competitivas em qualquer organização. Por meio destas será possível padronizar os serviços ofertados, bem como motivar os colaboradores a desempenharem suas funções da melhor maneira. Deste modo, tais práticas influenciarão diretamente a qualidade percebida por seus clientes finais.

No entanto, há ainda a necessidade de se investigar os efetivos ganhos que as políticas de treinamento exercem sobre a produtividade e os resultados financeiros desta organização. Sendo assim, abre-se esse eixo como oportunidade para o desenvolvimento de pesquisas futuras.

\section{Referências}

ARAGÓN-SÁNCHEZ, A.; BARBA-ARAGÓN, I.; SANZ-VALLE, R. Effects of training on business results. The International Journal of Human Resource Management, v. 14, n. 6, p. 956-980, 2003.

ARDIGÓ, C. M.; CAETANO, L.; DAMO, L. P. O turismo religioso e o processo de comunicação de marketing: um estudo do Santuário de Santa Paulina em Nova Trento - SC. Revista Turismo - Visão e Ação - Eletrônica, Vale do Itajaí, v. 18, n. 2, p.353-377, 2016.

ASSOCIAÇÃO DE HOTÉIS ROTEIROS DE CHARME. (s/d). Pousada do Sandi - Paraty - Rio de Janeiro. Disponível em: http://www.roteirosdecharme.com.br/pousadadosandi. Acesso em: 15 nov. 2019.

BAUM, T. Human Resource in Tourism: still waiting for change? A 2015 reprise. Tourism Management, v. 50, p. 204-212, 2015. 
BOOG, G. Manual de Treinamento e Desenvolvimento - Gestão e Estratégias. São Paulo: Pearson, 2013.

BOOKING.COM. 2017. Avaliações da Pousada do Sandi. Disponível em:

https://www.booking.com/reviews/br/hotel/pousada-do-sandi.pt-br.html?aid=356986;label=gog235jchotel-xb-br-pousadaNdoNsandi-unspec-br-com-L\%3Axb-O\%3AwindowsS10-B\%3Achrome-

N\%3AXX-S\%3Abo-U\%3Ac-H\%3As;sid=d3dfa8bf5c3434b036c2ef864d6b4ef5. Acesso em: 20 nov. 2017.

BOOKING.COM. 2020. Avaliações da Pousada do Sandi. Disponível em: https://www.booking.com/hotel/br/pousada-do-sandi.pt-br.html?aid=376377;label=bdotgy7L_infjQ8w7JjcliefRAS267778091953\%3Ap1\%3Ata\%3Ap1\%3Ap22.655.000\%3Aac\%3Aap\%3An eg\%3Afi\%3Atiaud-803460390643\%3Akwd-

334108349\%3Alp1001655\%3Ali\%3Adec\%3Adm\%3Appccp\%3DUmFuZG9tSVYkc2RIIyh9YXwxh KG0pUU-3JdcXtALQMg;sid=8e175e53d1da70324086aca72886f32e;dest_id=-

659504;dest_type $=$ city;dist $=0$;from_beach_non_key_ufi_sr=1;group_adults $=2$;group_children $=0$; hapo $\mathrm{s}=1$; hpos $=1$;no_rooms $=1 ;$ room $1=$ A\%2CA;sb_price_type=total;sr_order=popularity;srepoch $=1583162$ 428; srpvid=20ab6bde26c201bc;type=total;ucfs=1\&\#tab-reviews. Acesso em: 01 mar. 2020.

BRANCO, G. M.; RIBEIRO, J. L. D.; TINOCO, M. A. C. Determinantes da satisfação e atributos da qualidade em serviços de hotelaria. Produção, v. 20, n. 4, p. 576-588, 2010.

BRUYNE, P.; HERMMAN, J.; SCHOUTHEETE, M. Dinâmica da pesquisa em ciências sociais: os polos da prática metodológica. Rio de Janeiro: Francisco Alves, 1991.

BUIJTENDIJK, H.; TSCHUNKERT, K. Hotel industry expansion and sustainable development: A case study of Inle Lake, Myanmar. Research in Hospitality Management, v. 6, p. 9-23, 2016.

CÂNDIDO, I. Governança em hotelaria. Caxias do Sul, RS: EDUCS, 2001.

CAON, M.; CORRÊA, H. L. Gestão de serviços: lucratividade por meio de operações e de satisfação dos clientes. São Paulo: Atlas, 2016.

CASTELLI, G. Administração Hoteleira. Caxias do Sul, RS: EDUCS, 2003.

CASTELLI, G. Excelência em Hotelaria: uma abordagem prática. Rio de Janeiro: Qualitymark, 2005.

CASTELLI, G. Gestão hoteleira. São Paulo: Saraiva, 2016.

CENTURIÓN, L. Princípios e práticas de Revenue Management: gerenciamento de demanda, de receita e de distribuição. São Paulo: SENAC, 2014.

CHERAGHALIZADEH; R.; TÜMER, M. The effect of applied resources on competitive advantage in hotels: mediation and moderation analysis. Journal of Hospitality and Tourism Management, v. 31, p. 265-272, 2017.

CONCEIÇÃO, R. D. P.; FRAGA, T. F.; CONCEIÇÃO, M. P. Qualificação Profissional: um panorama comparativo entre hotéis e pousadas do primeiro distrito de Petrópolis - RJ. Turismo em Análise, v. 27, n. 1, p. 178-206, 2016. 
CORRÊA, H. L; CAON, M. Gestão de serviços: lucratividade por meio de operação e de satisfação dos clientes. São Paulo: Atlas, 2016.

CRESWELL, J. W. Research Design: qualitative, quantitative and mixed methods approaches. Thousand Oaks: Sage Publications Inc, 2003.

EMBRATUR - Instituto Brasileiro do Turismo. 2015. Turismo contribui com 9\% do PIB mundial. Disponível em: http://www.embratur.gov.br/piembratur-

new/opencms/salaImprensa/artigos/arquivos/Turismo_contribui_com_9_do_PIB_mundial.html. Acesso em: 13 fev. 2020.

ESTEBAN-LLORET, N. N.; ARAGÓN-SÁNCHEZ, A.; CARRASCO-HERNÁNDEZ, A. Institutional and competitive drivers on managers' training and organizational outcomes. Business Research Quartely, v. 17, p. 242-258, 2014.

EXPEDIA. 2017. Avaliações de Hóspedes. Disponível em: https://www.expedia.com.br/llha-GrandeBay-Hoteis-Pousada-Do-Sandi.h1514852.Hotel-Reservas. Acesso em: 17 dez. 2017.

EXPEDIA. 2020. Avaliações de Hóspedes. Disponível em: https://www.expedia.com.br/ParatyHoteis-Pousada-Do-Sandi.h1514852.Hotel-

Reservas?chkin $=16 \% 2 \mathrm{~F} 03 \% 2 \mathrm{~F} 2020 \&$ chkout $=17 \% 2 \mathrm{~F} 03 \% 2 \mathrm{~F} 2020 \&$ destType $=$ ADDRESS $\&$ destination $=$ Largo $\% 20 \mathrm{do} \% 20 \mathrm{Roz} \% \mathrm{C} 3 \% \mathrm{~A} 1 \mathrm{rio} \% 2 \mathrm{C} \% 201 \% 20$

\%20Centro\%20Hist\%C3\%B3rico\%2C\%20Paraty\%20-\%20RJ\%2C\%2023970-

$000 \% 2 \mathrm{C} \% 20$ Brasil\&neighborhoodId $=3000663597 \&$ pwaDialog=reviews\&pwa_ts $=1583162728013 \& \mathrm{r}$ eferrerUrl=aHR0cHM6Ly93d3cuZXhwZWRpYS5jb20uYnIvSG90ZWwtU2VhcmNo\&rfrr=HSR\&rm $1=\mathrm{a} 2 \&$ sort=recommended\&swpToggleOn=true\&top_cur=BRL\&top_dp=457\&x_pwa $=1$. Acesso em: 01 mar. 2020.

FERRARY, M. Investing in transferable strategic human capital through alliances in the luxury hotel industry. Journal of Knowledge Management, v. 19, n. 5, p. 1007-1028, 2015.

FILIERI, R.; ALGUEZAUI, S.; MCLEAY, F. Why do travelers trust TripAdvisor? Antecedents of trust towards consumer-generated media and its influence on recommendation adoption and word of mouth. Tourism Management, v. 51, p. 174-185, 2015.

FOHB - Fórum dos Operadores Hoteleiros do Brasil. 2017. Perspectiva de desempenho da hotelaria. Disponível em: http://fohb.com.br/wp-content/uploads/2017/11/Ed.-5-Perspectivas-deDesempenho-da-Hotelaria.pdf. Acesso em: 17 jan. 2020.

FU, H.; YANG, H.; CHU, K. Correlations among Satisfaction with Educational Training, Job Performance, Job Characteristics, and Person-Job Fit. Anthropologist, v. 17, n. 1, p. 65-74, 2014.

GHEBREGIORGIS, F.; KARSTEN, L. Human resource management and performance in a developing country: the case of Eritrea. The International Journal of Human Resource Management, v. 18, n. 2, p. 321-332, 2007.

GIL, A. C. Como elaborar projetos de pesquisa. São Paulo: Atlas, 2009.

GOMES, D.; TEODORO, R. Paradigmas Contemporâneos e as Contribuições dos Jogos e Simulações em Educação, Treinamento e Desenvolvimento do Potencial Humano. Revista da Micro e Pequena Empresa, Campo Limpo Paulista, v. 4, n. 2, p. 19-32, 2010.

Revista Acadêmica Observatório de Inovação do Turismo, v. 15, n. 2, agosto/2021 
GREGSON, P. Hotelaria na prática. Barueri, SP: Manole, 2009.

HAIR JR., J. F.; ANDERSON, R. E.; TATHAM, R. L.; BLACK, W. C. Análise Multivariada de Dados. São Paulo: Bookman, 2009.

HAYES, D. K.; NINEMEIER, J. D. Gestão de operações hoteleiras. São Paulo: Prentice Hall, 2005.

IBGE - Instituto Brasileiro de Geografia e Estatística. 2017. Pesquisa de Serviços de Hospedagem. Disponível em:

http://www.dadosefatos.turismo.gov.br/images/PESQUISA_DE_SERVI\%C3\%87O_DE_HOSPEDA GEM_2016_RELAT\%C3\%93RIO_MTUR_IBGE.pdf. Acesso em: 17 jan. 2020.

KAYAK. 2017. Avaliações da Pousada do Sandi. Disponível em:

https://www.kayak.com.br/hotels/Pousada-Do-Sandi,Paraty,Brasil-c47046-h116417/2017-12-07/201712-09/2adults?sort=rank_a. Acesso em: 17 nov. 2017.

KAYAK. 2020. Pousada do Sandi. Disponível em: https://www.kayak.com.br/hotels/Pousada-DoSandi,Paraty,Rio-de-Janeiro,Brasil-c47046-h116417/2020-03-03/2020-03-04/2adults?sort=rank_a. Acesso em: 01 mar. 2020.

LENZIARDI, R. A responsabilidade social corporativa e o desenvolvimento sustentável em meios de hospedagem de Paraty: uma análise exploratória. 2011. 131 f. Dissertação (Mestrado em Gestão Empresarial) - Fundação Getúlio Vargas, Escola Brasileira de Administração Pública e de Empresas, Rio de Janeiro, RJ, Brasil, 2011.

LIMA, T. B.; SILVA, J. F. Treinamento e hospitalidade: um estudo em hotéis de João Pessoa, Paraíba, Brasil. Revista Investigaciones Turísticas, Alicante, n. 15, p. 108-127, 2018.

MARRAS, J. P. Administração de recursos humanos: do operacional ao estratégico. São Paulo: Futura, 2011.

MICHAELS, E.; HANDFIELD-JONES, H.; AXELROD, B. A guerra pelo talento. Rio de Janeiro: Campus, 2002.

MILES, M. B.; HUBERMAN, A. M.; SALDAÑA, J. Análise de dados qualitativos: um manual metodológico. Thousand Oaks: Sage Publications, Inc., 2014.

MINCIOTTI, S. A.; SANTOLIA, F.; KASPAR, C. A. R. P. Identificação de Fatores Críticos de Sucesso para Monitoramento do Nível de Satisfação de Hóspedes de Hotéis. Turismo em Análise, São Paulo, v. 19, n. 1, p.155-173, 2008.

PEREIRA, Y. V.; LUCENA, E. A. O Papel dos Líderes nas Estratégias da Accor Hotels do Brasil. Turismo - Visão e Ação, Vale do Itajaí, v. 10, n. 1, p. 57-73, 2008.

PETROCCHI, M. Hotelaria: Planejamento e Gestão. São Paulo: Futura, 2002.

ROBLEDO, J. L. R.; ARÁN, M. V.; PÉREZ-ARANDA, J. Gestión del conocimiento y orientación al marketing interno en el desarrollo de ventajas competitivas en el sector hotelero. Investigaciones Europeas de Dirección y Economía de la Empresa, v. 21, p. 84-92, 2015. 
ROBSON, C. Real World Research Design: a resource for users of social research methods in applied settings. West Sussex, UK: John Wiley \& Sons Ltd., 2011.

RUS, R. V.; NEGRUSA, A. L. Online hotel booking systems in Romania. Procedia Economics and Finance, v. 15, p. 1235-1242, 2014.

SANTOS, M. G.; JESUS, K. C. B.; SILVA, J. C. S.; SILVA, A. S.; FRANCO, A. P. Como aprendem os empresários juniores no Brasil: um estudo quantitativo sobre as modalidades de aprendizagem organizacional. Revista Gestão e Planejamento, Salvador, v. 14, n. 3, p. 372-388, 2013.

SANTOS, R. A.; SILVA, L. P. Princípios e valores organizacionais: a questão do treinamento e a excelência dos serviços hoteleiros. Um estudo de caso na JW Marriott Rio de Janeiro. Revista Brasileira de Pesquisa em Turismo, v. 9, n. 3, p. 422-441, 2015.

SANTOS, R. A.; ALMEIDA, R. S. M.; MIRANDA, L. F. A sustentabilidade e a hotelaria carioca: critérios para um desenvolvimento integrado e participativo. Revista Turismo Visão e Ação, Vale do Itajaí, v. 23, n. 1, p. 191-215, 2021.

SEIFFERT, M. E. B. Auditoria de sistema de gestão: princípios, procedimentos e práticas com ênfase nas normas ISO (9001, 14001, 22000) e OHSAS 18001. São Paulo: Atlas, 2013.

SILVA, F. F.; LÚCIO, E. M. M.; BARRETO, L. M. T. S. Treinamento, desenvolvimento e educação de pessoas em turismo: case Disney. Revista Hospitalidade, São Paulo, v. 10, n. 2, p. 275-295, 2013.

SINGLETON JR, R. A.; STRAITS, B. C. Approaches Social Research. Oxford: Oxford University, Press, Inc., 2010.

SOUZA, B. C. S. Educação corporativa em hotéis: um estudo de caso no Hotel SESC Copacabana. Revista CULTUR, Ilhéus, ano 11, n. 3, p. 26-57, 2017.

TEIXEIRA, R. M. Competências e aprendizagem de empreendedores/gestores de pequenas empresas no setor hoteleiro. Revista Turismo em Análise, São Paulo, v. 22, n. 1, p. 195-219, 2011.

TRIPADVISOR. 2017. Pousada do Sandi. Disponível em:

https://www.tripadvisor.com.br/Hotel_Review-g303503-d519236-Reviews-Pousada_do_SandiParaty_State_of_Rio_de_Janeiro.html. Acesso em: 15 nov. 2017.

TRIPADVISOR. 2020. Pousada do Sandi. Disponível em: https://www.tripadvisor.com.br/Hotel_Review-g303503-d519236-Reviews-Pousada_do_SandiParaty_State_of_Rio_de_Janeiro.html\#REVIEWS. Acesso em: 01 mar. 2020

VARGAS, M. R. M. Treinamento e desenvolvimento: reflexões sobre os seus métodos. RAUSP Revista de Administração, São Paulo, v. 31, n. 2, p. 126-136, 1996.

VIEIRA, E. V. Qualidade em serviços hoteleiros: a satisfação do cliente é função de todos. Caxias do Sul, RS: EDUCS, 2004.

VIEIRA, A.; SALVE, C. M. G.; CORRÊA, M. L. Práticas de treinamento e de desenvolvimento de pessoas no setor hoteleiro de Belo Horizonte. Revista Turismo Visão e Ação - Eletrônica, Vale do Itajaí, v. 12, n. 1, p. 23-48, 2010.

Revista Acadêmica Observatório de Inovação do Turismo, v. 15, n. 2, agosto/2021 
UBEDA-GARCIA, M.; MARCO-LAJARA, B.; SABATER-SEMPERE, V.; GARCÍA-LILLO, F. Does training influence organisational performance? Analysis of the Spanish hotel sector. European Journal of Training and Development, v. 37, n. 4, p. 380-413, 2013.

UBEDA-GARCÍA, M.; CORTÉS, E. C.; MARCO-LAJAR, B.; ZARAGOZA-SÁEZ, P. Strategy, training and performance fit. International Journal of Hospitality Management, v. 42, p. 100-116, 2014.

UNWTO - World Tourism Organization. 2008. Tourism Highlights. Disponível em: https://www.eunwto.org/doi/pdf/10.18111/9789284413591. Acesso em: 15 dez. 2020.

UNWTO - World Tourism Organization. 2011. Tourism Highlights. Disponível em: https://www.eunwto.org/doi/pdf/10.18111/9789284413935. Acesso em: 15 dez. 2020.

UNWTO - World Tourism Organization. 2016. Tourism Highlights. Disponível em: https://www.eunwto.org/doi/pdf/10.18111/9789284419029. Acesso em: 15 dez. 2020.

VEAL, A. J. Metodologia de pesquisa em lazer e turismo. São Paulo: Aleph, 2011.

WALKER, J. R. Introdução à hospitalidade. Barueri, SP: Manole, 2002.

YANG, J. Antecedents and consequences of job satisfaction in the hotel industry. International Journal of Hospitality Management, v. 29, p. 609-619, 2010.

YIN. R. K. Estudo de caso: planejamento e métodos. Porto Alegre: Bookman, 2005. 